\title{
Energy hub modeling to minimize residential energy costs considering solar energy and BESS
}

\author{
Thanhtung HA ${ }^{1}$, Yongjun ZHANG ${ }^{1}$, V. V. THANG ${ }^{2}$, \\ Jianang HUANG ${ }^{1}$
}

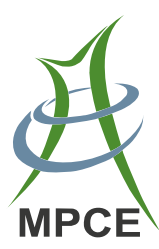

\begin{abstract}
This paper aims to optimize total energy costs in an operational model of a novel energy hub (EH) in a residential area. The optimization problem is set up based on daily load demand (such as electricity, heat, and cooling) and time-of-use (TOU) energy prices. The extended EH model considers the involvement of solar photovoltaic (PV) generation, solar heat exchanger (SHE), and a battery energy storage system (BESS). A mathematical model is constructed with the objective of optimizing total energy cost during the day, including some constraints such as input-output energy balance of the $\mathrm{EH}$, electricity price, capacity limitation of the system, and charge/discharge power of BESS. Four operational cases based on different EH structures are compared to assess the effect of solar energy applications and BESS on the operational efficiency. The results show that the proposed model predicts significant changes to the characteristics of electricity and gas power bought from utilities, leading to reduced total
\end{abstract}

CrossCheck date: 20 February 2017

Received: 14 October 2016/ Accepted: 20 February 2017/Published online: 10 April 2017

(C) The Author(s) 2017. This article is an open access publication

$\triangle$ Thanhtung HA

1741984944@qq.com

Yongjun ZHANG

zhangjun@scut.edu.cn

V. V. THANG

thangvvhtd@tnut.edu.vn

Jianang HUANG

jianang.huang@qq.com

1 School of Electric Power, South China University of Technology Guangzhou, Guangzhou, China

2 Department of Electric Power Systems, Thai Nguyen University of Technology (TNUT), Thai Nguyen, Vietnam energy cost compared to other cases. They also indicate that the model is appropriate for the characteristics of residential loads.

Keywords Natural gas price, Electricity price, Energy Hub, Optimal operation, General algebraic modeling system (GAMS), Solar, Battery energy storage system (BESS)

\section{Introduction}

In recent years, the formation and development of the Energy Internet (EI) through energy hubs (EH) [1] have shown a new direction towards achieving global energy security. Heat energy and electrical energy are two types of primary energy that account for a significant proportion of the total current demand. The combination of heat and power is a big step towards the higher performance of the system by considering different energy types simultaneously rather than focusing on one type of energy (i.e., electrical energy) as discussed in the previous research [2-5].

Rapidly increasing urbanization leads to suddenly growing residential energy use to meet various demands. Typical EH models of residential energy use include electricity, heat, and cool. The establishment and operation of residential $\mathrm{EH}$ attract lots of attention from scientists: an EH optimization model for a household was designed with the objective of minimizing energy cost in [6, 7]; $\mathrm{EH}$ modeling of domestic appliances in residential areas in Canada was conducted in [8], solving problems of peak load, minimal carbon dioxide emission, and energy usage costs; and a model suitable for the residential loads was set up in $[9,10]$ considering real time pricing for optimal operation of EH. 
Along with the development of the EI, renewable energy and energy storage technology are the two solutions being rapidly developed under the pressure of rising energy demand in modern society. In recent years, solar photovoltaic (PV) generation and solar heat exchanger (SHE) have been widely adopted through shortened construction time due to their modular structure and fewer restrictions on installation space [11-13]. These clean energy sources will be well adapted to loads in residential areas. However, before the concept of an EH appeared at the Swiss Federal Institute of Technology in Zurich [14, 15], no research exploited the use of solar energy in a coordinated way, including heat and electricity, rather than individually. Therefore, EH modeling and optimal operation need to consider these two types of energy to fully improve the efficiency of solar energy. Recently, a study [9] constructed an EH operational model to minimize energy cost and emission cost for a typical house in the UK in which solar energy (electricity and heat supply via PV and SHE) was used to replace proportions of electricity and gas bought from utilities. However, the EH structure did not fit with the characteristics of residential loads because the output only considered the use of electricity and heat power; in addition, the need for cooling is also very high in some climates.

Battery energy storage systems (BESS) are a fundamental solution to improve power supply reliability and economic efficiency of PV. For example, [16] coordinated BESS with PV in planning problems to reduce investment costs, operating and environmental pollution; [17] obtained improved economic efficiency by adjusting the load curve to reduce purchasing power costs of the system. Besides, the BESS can be used to adjust the load curve by storing electricity in off-peak hours and generating back to the grid during peak hours $[18,19]$. Hence, a BESS is an efficient energy storage method which is mentioned in some studies about the distribution grid, and there are many EH models taking into account energy storage devices to improve the operational efficiency of the system $[6,8,9,20-23]$. But so far, there is no research about the involvement of BESS as an integrated part of an EH model.

Generally speaking, PV and SHE have transformed energy usage in residential areas, while BESS are becoming important. It is very important to model an EH which includes PV, SHE and BESS to improve the operational efficiency of multiple forms of energy consumption. Therefore, this study aims to present an extended EH model to optimize total energy use costs for loads in residential areas. This extended model considering the involves solar energy (provided by PV and SHE) combined with BESS. The proposed structure uses both air-conditioners (AC) and absorption chillers (ACh) simultaneously to meet the cooling demands of loads in residential areas and to enhance the flexibility of converting between different types of energy.

Nowadays, optimization has been widely applied in scientific research to solve practical problems. Some outstanding fields using optimizing method are meteorology and natural calamities [24], irrigation [25], and environmental factors [26]. The use of optimizing methods is an increasing tendency in the energy field. Recent research about the optimal operation of an EH has used different approaches, different objective functions and constraints, and diverse tools including high-level programming languages such as Matlab, Fortran, Delphi, $\mathrm{C}++$ [27]. A highlevel programming language widely used in the optimization of EH, the general algebraic modeling system (GAMS) $[6,10,21,28,29]$, uses built-in algorithms (solvers) [30]. Therefore, this study uses language GAMS in order to solve the optimal operational problem of $\mathrm{EH}$, based on the energy cost to supply residential area loads. The objective is to minimize the total energy cost of the system. The resulting program will be more flexible than other available application programs, along with fulfilling consumer demands.

The remainder of the paper is structured as follows: Section 2 presents the basic structure of an $\mathrm{EH}$; the complete EH model is proposed considering solar energy and BESS. The role of BESS technology in managing solar energy through SHE and PV is proposed in Section 3. Section 4 introduces the objective function and other mathematical constraints of the optimization model. Simulation results for four cases with different structures are compared in Section 5 to assess the impact of solar energy (PV, SHE) and BESS on the operational efficiency of EH, especially the maximum capacity use of BESS. Finally, conclusion and future work are provided in Section 6.

\section{EH model for residential areas load}

\subsection{Description}

The general EH topology is shown in Fig. 1, where different types of energy are connected through conversion, control and storage.

Overall, the structures of an EH include input power, such as electricity and gas, which are named $E_{\mathrm{e}}$ and $E_{\mathrm{g}}$ respectively, and output power, such as electricity and heat, which are named $L_{\mathrm{e}}$ and $L_{\mathrm{h}}$ respectively. In addition, this $\mathrm{EH}$ also allows the participation of distributed generation (DG) with input $E_{\mathrm{DG}}$ and output $L_{\mathrm{DG}}$. The features of storage $\left(\mathrm{S}_{1}, \mathrm{~S}_{2}\right)$ and conversion $\left(\mathrm{c}_{1}, \mathrm{c}_{2}\right)$ of electricity and heat energy are also included. The EH model is mathematically described using the following equation [31]: 


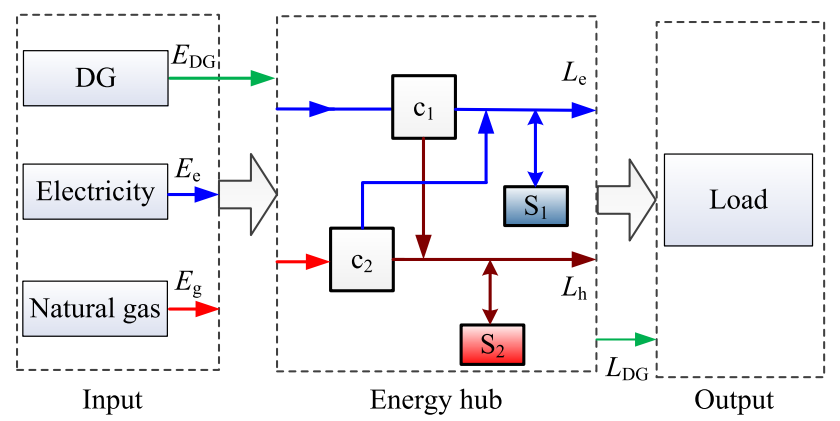

Fig. 1 EH topology

$$
\left[\begin{array}{c}
L_{1} \\
L_{2} \\
\vdots \\
L_{n}
\end{array}\right]=\left[\begin{array}{cccc}
c_{11} & c_{12} & \cdots & c_{1 m} \\
c_{21} & c_{22} & \cdots & c_{2 m} \\
\vdots & \vdots & \ddots & \vdots \\
c_{n 1} & c_{n 2} & \cdots & c_{n m}
\end{array}\right]\left[\begin{array}{c}
E_{1} \\
E_{2} \\
\vdots \\
E_{m}
\end{array}\right]
$$

where $c_{i j}$ is the connecting factor that indicates the relationship between the $i$ th input power and the $j$ th output power; $E_{i}, i=1,2 \ldots, m$, is the power input; $L_{j}, j=1,2 \ldots$, $n$ is the converted power output.

\subsection{EH modeling for residential areas load}

The rapid urbanization process has led to the increasing demand for electricity, heat, and cooling. Reference [10] proposed an EH model to show that supplying electricity and heat loads with conversion by micro turbine (MT) and $\mathrm{AC}$ was quite flexible; it raises energy efficiency by $11.6 \%$ compared with the traditional method. But the cooling loads were not included. Recent EH research on combined cooling, heat, and power (CCHP) primarily met the needs for the cooling demand of the loads through $\mathrm{AC}$ or $\mathrm{ACh}$ [20-23]. However, there is no model that considers the use of these two devices at the same time to increase flexibility, by supporting the conversion from both electricity and heat to cooling. Therefore, the basic EH structure shown in Fig. 2 is proposed, wherein central air conditioning systems $\mathrm{AC}$ and $\mathrm{ACh}$ meet the diversity of cooling loads.

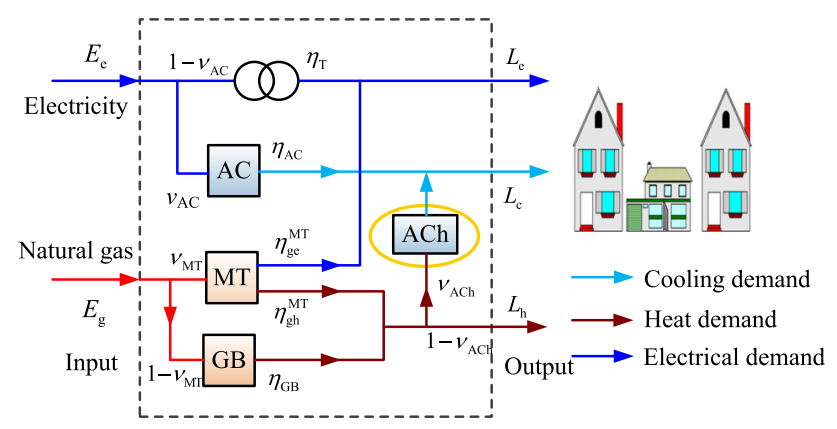

Fig. 2 Basic structure of EH for residential loads
As more and more DG and energy storage devices are installed in distribution systems and residential areas, research in that field will help to promote energy development. The residential load is mainly distributed in the delta region; therefore, it is necessary to choose suitable types of DG and energy storage system. An extended EH model for residential areas loads, considering solar energy and energy storage, is proposed as shown in Fig. 3. It can be flexibly installed and used, because solar energy is provided as electricity (through PV) and heat (through SHE), and the solar PV electricity is managed with an energy storage system (the BESS). The extended model is ensured to meet the residents' energy demand (electricity, heat, and cooling), Electricity energy $L_{\mathrm{e}}$ is supplied through the distribution grid, the MT, and solar PV. Cooling energy $L_{\mathrm{c}}$ is provided by the $\mathrm{AC}$ and the $\mathrm{ACh}$; heat energy $L_{\mathrm{h}}$ is supplied by the MT, a gas boiler (GB) and partly from SHE. Therefore, through this model, the demands for heat, electricity, and cooling energy can be transferred flexibly between devices, along with fully exploiting the use of solar energy.

As the energy price for residential areas is assumed to comprise a time of use (TOU) electricity price and a constant gas price, this research does not include a thermal storage system in order to reduce the investment cost and the complexity of $\mathrm{EH}$.

\section{Solar and BESS technologies}

\subsection{Solar}

The energy of solar radiation can be converted into direct current electricity through PV panels or into heat by SHE [9]. These devices do not pollute the local environment; hence, they are suitable to be installed in residential areas as shown in Fig. 4 and Fig. 5

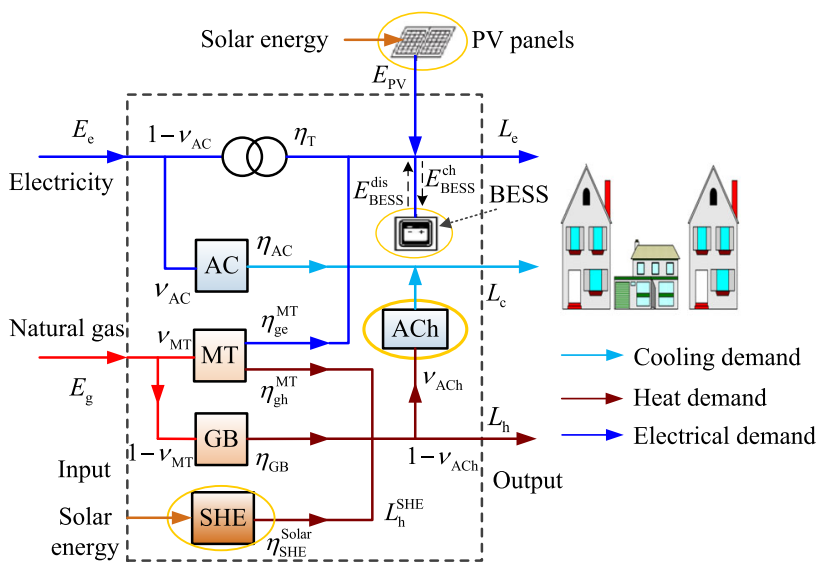

Fig. 3 Extended EH model for residential loads 
The output power of PV generation and SHE depends on the intensity of solar radiation. Solar radiation varies both in time and space; but for solar panels and SHE that are installed in a fixed location, the influence of space can be ignored. Therefore, the output power of PV generation and SHE can be described by functions of time.

\subsection{BESS technology}

BESS has been the leading energy storage technologies, with advantages in energy density and high efficiency, which can work over both short and long periods due to low direct energy use or self-discharge. Therefore, BESS has been widely applied in distributed grids [32]. BESS consists of different storage technologies referred to as 'batteries'. Examples of such battery technologies include [33, 34] lead acid batteries, sodium sulphur batteries, lithium-ion batteries, and nickel batteries, each of which has specific characteristics and economic effectiveness.

The chemical technology most widely used today is a lead-acid battery, which has low investment and maintenance costs and small self-discharge coefficient, but suffers from low life expectancy and pollutes the environment $[35,36]$. The sodium-sulphur battery is an interesting research topic for new applications because it has high energy density, low investment and operational costs, long life cycle, deep discharge ability, and high pulse power capacity, although this technology works at high temperature [36]. Similarly, the flow battery, such as vanadium redox battery (VRB) and zinc bromine battery ( $\mathrm{ZnBr})$, can be manufactured with high energy capacity, but their low energy density and very high investment costs have limited their application [37].

Lithium-ion (Li-ion) and nickel-cadmium (Ni-Cd) battery technologies have attracted much concern from different researchers. Factors such as high energy density or high efficiency contribute to the attractiveness of such technologies. They have got significant access to the field of consuming electronics and hybrid transport [35].

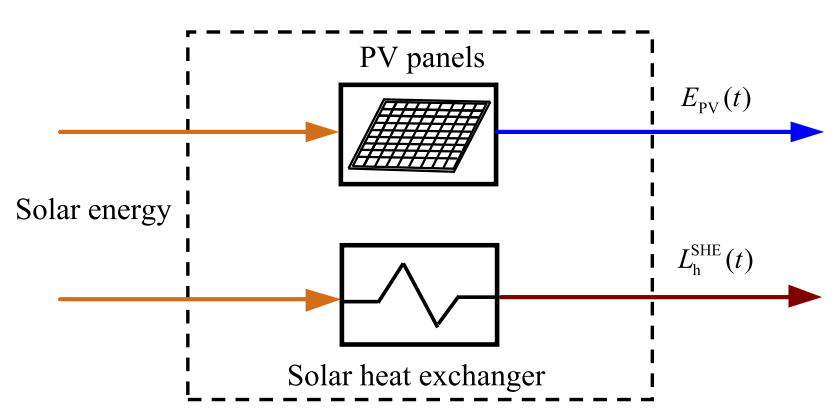

Fig. 4 Model of solar electricity and heat generation for residential areas

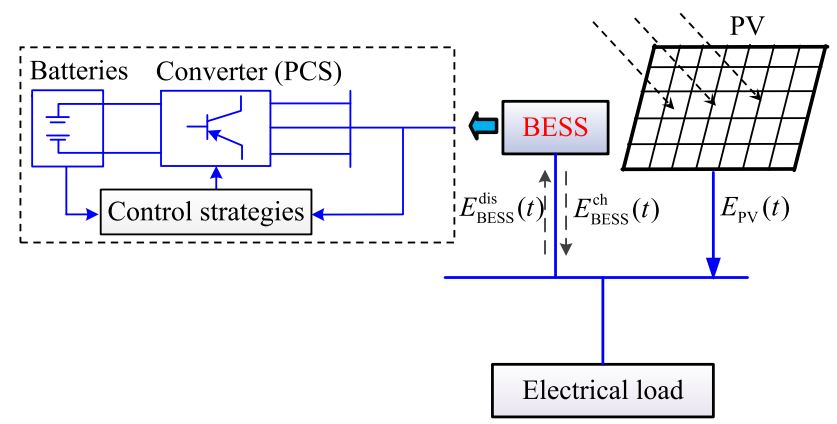

Fig. 5 Combination model of a BESS and PV panels

The output power of PV generation depends on the intensity of solar radiation which varies daily; TOU energy prices also change with a daily profile. Therefore, this paper concentrates on the problem of the optimal use of BESS: storing electricity in off-peak hours and supplying the load during peak hours.

The optimal operation problem of an EH is presented in Section 4. So as to minimize the cost of residential energy use, we need to optimize the input electricity and heat, within the constraints of the rated charging and discharging power of the BESS when it is used from time to time during the day. The cost objective function is minimized within the constraints on conversion efficiency, capacity limitations of devices in the system, energy balance, conversion limitations, and the charging and discharging rate of the BESS.

\section{Mathematical model}

\subsection{Objective function}

The total energy cost depends on the daily consumption of electricity and heat. The objective function is given as:

$\min \sum_{t=1}^{24}\left[E_{\mathrm{e}}(t) c_{\mathrm{e}}(t)+E_{\mathrm{g}}(t) c_{\mathrm{g}}(t)\right]$

where $E_{\mathrm{e}}(t)$ and $E_{\mathrm{g}}(t)$ are the received electricity and natural gas, respectively, at the EH input at hour $t$; and $c_{\mathrm{e}}(-$ $t)$ and $c_{\mathrm{g}}(t)$ are the electricity and natural gas prices at hour $t$, respectively.

\subsection{Constraints}

\subsubsection{Energy balance}

\section{1) Energy balance constraints of the EH}

Based on the operating principle of the extended EH model which was introduced in Section 2.2, the relationship between the energy demands $L_{\mathrm{e}}(t), L_{\mathrm{h}}(t)$ and $L_{\mathrm{c}}(t)$, and 
energy purchased from system $E_{\mathrm{e}}(t)$ and $E_{\mathrm{g}}(t)$ at time $t$ is expressed by:

$$
\left\{\begin{array}{c}
L_{\mathrm{e}}(t)=E_{\mathrm{e}}(t)\left(1-v_{\mathrm{AC}}(t)\right) \eta_{\mathrm{T}}+E_{\mathrm{g}}(t) v_{\mathrm{MT}}(t) \eta_{\mathrm{ge}}^{\mathrm{MT}} \\
\quad+E_{\mathrm{BESS}}^{\mathrm{dis}}(t)-E_{\mathrm{BESS}}^{\mathrm{ch}}(t)+E_{\mathrm{PV}}(t) \\
L_{\mathrm{h}}(t)=\left[E_{\mathrm{g}}(t)\left(v_{\mathrm{MT}} \eta_{\mathrm{gh}}^{\mathrm{MT}}+\left(1-v_{\mathrm{MT}}\right) \eta_{\mathrm{GB}}\right)+L_{\mathrm{h}}^{\mathrm{SHE}}(t)\right] \\
\quad \cdot\left(1-v_{\mathrm{ACh}}\right) \\
L_{c}(t)=E_{\mathrm{e}}(t) v_{\mathrm{AC}}(t) \eta_{\mathrm{e}}^{\mathrm{AC}}+\left[E _ { \mathrm { g } } ( t ) \left(v_{\mathrm{MT}} \eta_{\mathrm{gh}}^{\mathrm{MT}}\right.\right. \\
\left.\left.\quad+\left(1-v_{\mathrm{MT}}\right) \eta_{\mathrm{GB}}\right)+L_{\mathrm{h}}^{\mathrm{SHE}}(t)\right] v_{\mathrm{ACh}} \eta_{\mathrm{h}}^{\mathrm{ACh}}
\end{array}\right.
$$

where $E_{\mathrm{BESS}}^{\mathrm{ch}}(t), E_{\mathrm{BESS}}^{\mathrm{dis}}(t)$ are the charge and discharge power of BESS at hour $t$, respectively; $E_{\mathrm{PV}}(t)$ is the electric power output of the PV panels at hour $t ; v_{\mathrm{AC}}(t), v_{\mathrm{MT}}(t)$, $v_{\mathrm{ACh}}(t)$ are the dispatch ratios of electricity, natural gas, and heat conversion at hour $t$, respectively, as indicated in Fig. $3 ; \eta_{\mathrm{ge}}^{\mathrm{MT}}, \eta_{\mathrm{gh}}^{\mathrm{MT}}$ are the gas-to-electricity and heat conversion efficiency of the MT; $\eta_{\mathrm{T}}, \eta_{\mathrm{GB}}, \eta_{\mathrm{h}}^{\mathrm{ACh}}, \eta_{\mathrm{e}}^{\mathrm{AC}}$ are efficiency of transformers, $\mathrm{GB}, \mathrm{ACh}$, and $\mathrm{AC}$, respectively; $L_{\mathrm{h}}^{\mathrm{SHE}}(t)$ is the heat power output of the SHE at hour $t$.

\section{2) Energy balance constraints of the BESS}

The characteristics of PV output often repeat in a cycle of 24 hours. Hence, assuming that the BESS should return to the same state in 24 hours, the constraint on BESS energy balance is expressed as:

$$
\left\{\begin{array}{l}
\sum_{t=1}^{H_{1}} \eta_{\mathrm{BESS}} E_{\mathrm{BESS}}^{\mathrm{ch}}(t)=\sum_{t=1}^{H_{2}} E_{\mathrm{BESS}}^{\mathrm{dis}}(t) \\
H_{1}+H_{2}=24
\end{array}\right.
$$

where $\eta_{\mathrm{BESS}}$ is the efficiency of the BESS; and $H_{1}$ and $H_{2}$ are the total charging time and discharging time of the BESS per day, respectively.

\subsubsection{Charging and discharging time of BESS}

The BESS can work in charge or discharge mode and can be charged from PV or the system depending on the operating model. The charge/discharge of the BESS can be expressed through two binary variables $\delta_{\mathrm{BESS}}^{\mathrm{dis}}\left(t_{i}\right)$ and $\delta_{\mathrm{BESS}}^{\mathrm{ch}}\left(t_{i}\right)$ so that we will get:

$$
\left\{\begin{array}{l}
\delta_{\mathrm{BESS}}^{\mathrm{ch}}\left(t_{i}\right) E_{\mathrm{BESS}}^{\mathrm{ch}}\left(t_{i}\right)>0 \Leftrightarrow \delta_{\mathrm{BESS}}^{\mathrm{ch}}\left(t_{i}\right)=1 \\
\delta_{\mathrm{BESS}}^{\mathrm{dis}}\left(t_{i}\right) E_{\mathrm{BESS}}^{\mathrm{dis}}\left(t_{i}\right)>0 \Leftrightarrow \delta_{\mathrm{BESS}}^{\mathrm{dis}}\left(t_{i}\right)=1 \\
\delta_{\mathrm{BESS}}^{\mathrm{dis}}\left(t_{i}\right)+\delta_{\mathrm{BESS}}^{\mathrm{ch}}\left(t_{i}\right)=1 \\
\delta_{\mathrm{BESS}}^{\mathrm{dis}}\left(t_{i}\right) \times \delta_{\mathrm{BESS}}^{\mathrm{ch}}\left(t_{i}\right)=0
\end{array}\right.
$$

\subsubsection{Power limitation}

The electricity and natural gas received at hub inputs are limited due to the following constraints:

$$
\begin{aligned}
& E_{\mathrm{e}}(t) \leq E_{\mathrm{e}}^{\max } \\
& E_{\mathrm{g}}(t) \leq E_{\mathrm{g}}^{\max }
\end{aligned}
$$

where $E_{\mathrm{e}}^{\max }$ and $E_{\mathrm{g}}^{\max }$ are the maximum allowable power of electrical energy and natural gas.

The charge/discharge power capacity of the BESS should not exceed the permissible limits to ensure stable performance and extend the life of the equipment, which is expressed as:

$0 \leq E_{\mathrm{BESS}}^{\mathrm{dis}}(t) \leq E_{\mathrm{BESS}}^{\max }$

$0 \leq E_{\mathrm{BESS}}^{\mathrm{ch}}(t) \leq E_{\mathrm{BESS}}^{\max }$

where $E_{\mathrm{BESS}}^{\max }$ is the maximum power capacity of the BESS.

\subsubsection{Conversion limitations}

The optimal operation of EH is based on the ability to control the flow of AC, ACh, and MT devices. Therefore, the conversion limits of the devices above at time $t$ include $v_{\mathrm{AC}}(t), v_{\mathrm{MT}}(t)$ and $v_{\mathrm{ACh}}(t)$, which are state variables that show what proportion of input power is directed through the corresponding devices from time to time. Constraints of these state variables are expressed in equations as:

$0 \leq v_{\mathrm{AC}}(t) \leq 1$

$0 \leq v_{\mathrm{MT}}(t) \leq 1$

$0 \leq v_{\mathrm{ACh}}(t) \leq 1$

\subsubsection{Energy prices}

For a residential area, the energy prices are based on the TOU principle $[38,39]$. A TOU price is the simplest form of dynamic price. The primary objective of the pricing program is to encourage less energy consumption during the peak hours.

Electricity prices vary according to the following three levels:

$c_{\mathrm{e}}(t)=\left\{\begin{array}{cl}c_{\mathrm{e}}^{\text {max }} & \text { On-peak } \\ c_{\mathrm{e}}^{\text {normal }} & \text { Mid-peak } \\ c_{\mathrm{e}}^{\text {min }} & \text { Off-peak }\end{array}\right.$

where $c_{\mathrm{e}}^{\max }, c_{\mathrm{e}}^{\text {normal }}, c_{\mathrm{e}}^{\min }$ are the electricity price, when demands for electricity are highest (On-peak), moderate (Mid-peak), and low (Off-peak), respectively.

Energy prices play a critical role in the objective function (2). The optimization problem considers the prices of natural gas and electricity. The natural gas price in residential areas is a constant and expressed by [40]:

$c_{\mathrm{g}}(t)=\mathrm{const}[\$ / \mathrm{kWh}]$

Thus, the requirement in this part is to solve the optimization problem to find solution sets $X=\left\{E_{\mathrm{g}}(t)\right.$, $\left.E_{\mathrm{e}}(t), v_{\mathrm{ACh}}(t), v_{\mathrm{MT}}(t), E_{\mathrm{BESS}}^{\mathrm{dis}}(t), E_{\mathrm{BESS}}^{\mathrm{ch}}(t)\right\}$ satisfying the objective function (2) within constraints (3-14). 


\section{Simulation result}

The extended model in Fig.3 has the following advantages.

1) Fully exploiting solar energy in the forms of electricity and heat through PV generation and SHE.

2) Considering the presence of the BESS which has been used very effectively in the distribution grid to provide efficient energy storage and timely response to changes in system conditions.

3) Separating the cooling demand of loads, by proposing a structure using both $\mathrm{AC}$ and $\mathrm{ACh}$ devices to increase the ability to convert from electricity and heat to cooling.

To highlight the superiority of the proposed model, an optimal operation of an EH has been calculated in 4 cases with different structures (Table 1), to assess the impacts of solar energy (PV, SHE) and BESS on the operational efficiency of an EH. The data used to model residential loads, energy prices, EH components, and solar energy inputs are introduced in Section 5.1, and the results are given in Section 5.2. Note that all units refer to electrical or thermal energy according to their context.

\subsection{Database}

Data applied to the 4 cases, as shown in Table 1, include electricity, heating, and cooling demand on a typical day; electricity price; natural gas price; devices' parameters and capacity limits of the system; and parameters of PV generation, SHE and BESS, which are explained in detail as follows.

\subsubsection{Electricity, heat, and cooling demands}

Load parameters of residential areas including electricity, heat, and cooling demand are based on references [6] and [20] and plotted in Fig. 6. The highest electricity consumption at peak hour reaches $3.3 \mathrm{MW}$, and the heating and cooling demand for daily needs are lower, their highest values being $0.95 \mathrm{MW}$ and $0.48 \mathrm{MW}$, respectively.

Table 1 Proposed hub components in 4 simulated cases

\begin{tabular}{llll}
\hline Case & Base EH & Solar & BESS \\
\hline 1 & $\sqrt{ }$ & & \\
2 & $\sqrt{ }$ & $\sqrt{ }$ & \\
3 & $\sqrt{ }$ & & $\sqrt{ }$ \\
4 & $\sqrt{ }$ & $\sqrt{ }$ & $\sqrt{ }$ \\
\hline
\end{tabular}

\subsubsection{Energy prices}

Electricity and gas prices are assumed as shown in Fig. 7, in which the gas price is assumed to be a fixed rate. Taken from [40], it is assumed to be 5.5 cents/kWh. The most common time-variant electricity price for residential customers is TOU pricing [38]. Three different price levels are introduced at TOU price during each day [39].

\subsubsection{Device parameters and power limitations of the system}

The parameters are given in Table 2 and Table 3 based on $[6,20]$.

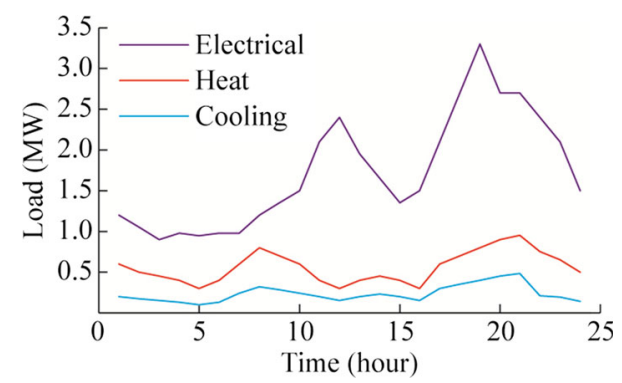

Fig. 6 Electrical, heat, and cool demand in a sample day (output)

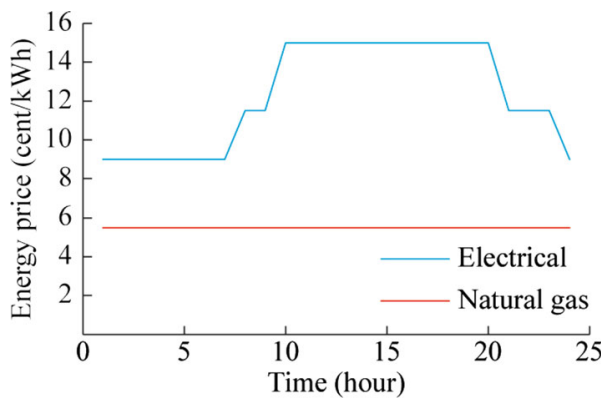

Fig. 7 Electricity and gas prices

Table 2 Efficiency data

\begin{tabular}{llllll}
\hline$\eta_{\mathrm{e}}^{\mathrm{AC}}$ & $\eta_{\mathrm{ge}}^{\mathrm{MT}}$ & $\eta_{\mathrm{GB}}$ & $\eta^{\mathrm{T}}$ & $\eta_{\mathrm{gh}}^{\mathrm{MT}}$ & $\eta_{\mathrm{h}}^{\mathrm{ACh}}$ \\
\hline 0.85 & 0.4 & 0.88 & 0.95 & 0.5 & 0.9 \\
\hline
\end{tabular}

Table 3 Capacity constraint data

\begin{tabular}{ll}
\hline$E_{\mathrm{e}}^{\max }(\mathrm{MW})$ & $E_{\mathrm{g}}^{\max }(\mathrm{MW})$ \\
\hline 5 & 3 \\
\hline
\end{tabular}




\subsubsection{Parameters of PV, SHE and BESS}

Selecting parameters (installed capacity and the performance of equipment) of PV and BESS devices has a great impact on the economic and technical indicators of the model. This study mainly solves the problem of optimal operation to examine the effectiveness of the devices and their impact on the system's performance. Based on the parameters introduced in [9], this calculation is performed based on the assumption that the PV and SHE sources installed have the output power characteristics over 24 hours as shown in Fig. 8. During 1 AM to 4 AM and 7 PM to $12 \mathrm{AM}$, due to the very low intensity of solar radiation, it can be assumed that the output power of these two devices is zero. At $12 \mathrm{PM}, \mathrm{PV}$ generation produces its maximum power capacity of $0.5 \mathrm{MW}$, and the heat energy from the SHE reaches the its highest level of $0.25 \mathrm{MW}$, due to the maximum intensity of solar radiation.

Based on the assumption that the BESS uses a NaS battery with 10 years life cycle and having high efficiency of 0.9 , the BESS has a power of $450 \mathrm{~kW}$ and a capacity of $4200 \mathrm{kWh}$.

\subsection{Optimization results}

The proposed model is programmed in the GAMS programming language, using solver BONMIN. GAMS is a programming language that allows programming the optimization problems with vast and complex models [30]. The model is presented briefly and simply, allowing the use of user-defined algebra within calculation algorithm as shown in the block diagram in Fig. 9.

The results for optimal operation of an EH in the 4 cases in Table 1 are detailed as follows.

\subsubsection{Case 1}

The calculated input energy of the basic EH (without considering solar energy and the BESS) is plotted in Fig. 10(a). The optimized result shows that the input electricity demand from the system has its highest value of 2.39 MW during peak hour (at 7 PM). In this model, the

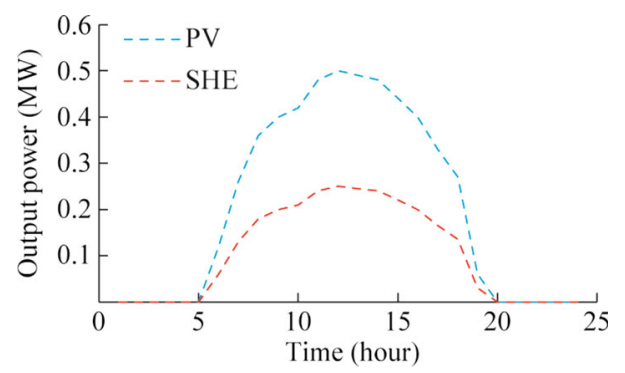

Fig. 8 Output power characteristics of PV and SHE within a day remaining energy is supplied through the MT, leading to relatively high natural gas demand. Its highest value reaches 3.0 MW at 9 PM. Relative electricity and gas prices, the ratio of electricity and heating demand, and conversion efficiencies determine when the MT and GB are used compared to electricity. This is why gas consumption continues to rise after $7 \mathrm{PM}$, to meet heating and cooling demand, which electricity demand is by then declining.

\subsubsection{Case 2}

The EH structure in Case 2 adds solar PV generation and SHE to the basic EH model. The calculated energy input to the system is illustrated in Fig. 10(b), which shows that the additional heat from SHE and electricity from PV generation significantly change the energy demand. Particularly in comparison to the first case, the highest power demand was $2.35 \mathrm{MW}$ at $7 \mathrm{PM}$ (decreased 1.67\%). Especially at 12 PM, when both PV and SHE provided the maximum capacity of $0.5 \mathrm{MW}$ and $0.25 \mathrm{MW}$ respectively, the demand for power from the system decreased from 2.13 MW to $1.78 \mathrm{MW}$. It is found that the EH with solar energy has brought a significant improvement in efficiency compared to the EH model of Case 1. Although the investment cost of solar energy is high, it is very effective in reducing environmental pollution. The total cost of energy bought

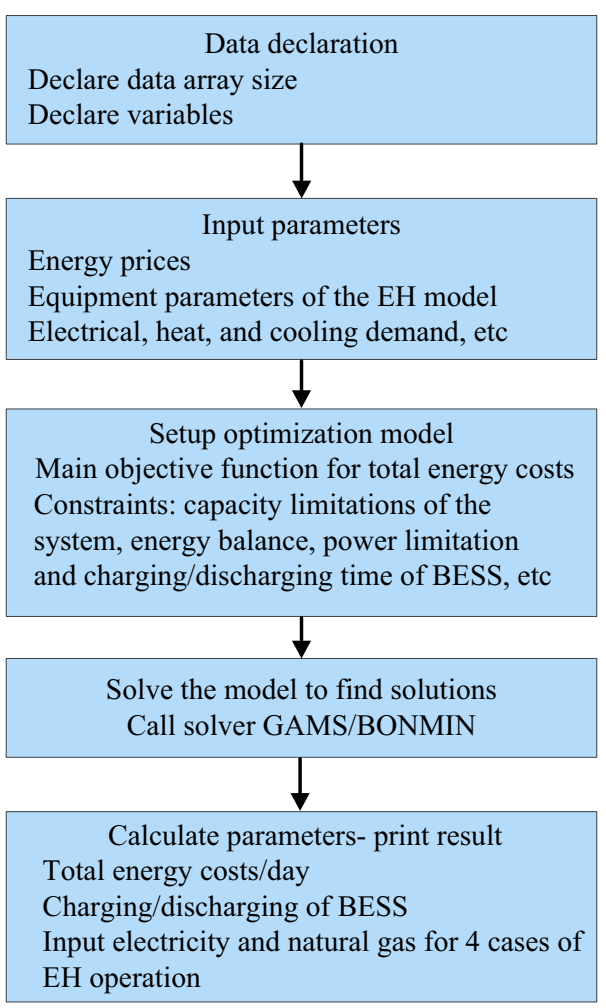

Fig. 9 Problem solving steps using GAMS 


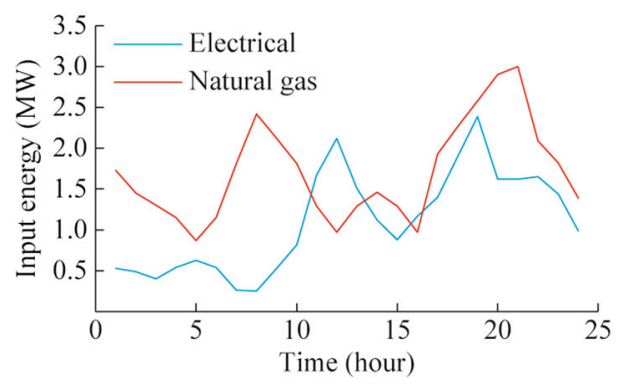

(a)

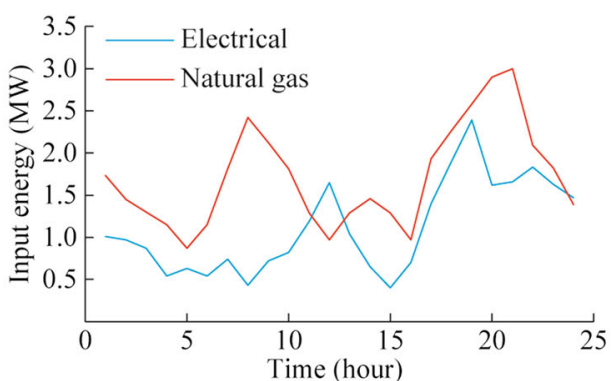

(c)

Fig. 10 Input electricity and natural gas for 4 cases of EH operation

Table 4 Total energy costs of 4 cases

\begin{tabular}{lllll}
\hline Case & 1 & 2 & 3 & 4 \\
\hline Total energy costs (\$/day) & 5760 & 5050 & 5648 & 4893 \\
\hline
\end{tabular}

from utilities in Case 2 is reduced significantly compared to Case 1, as shown in Table 4.

\subsubsection{Case 3}

The EH model, in this case, is constructed to assess the impact of a BESS on the operational efficiency of the EH, especially to optimize the BESS power capacity. The result for energy bought from utilities is shown in Fig. 10(c). Compared to the optimization result in Case 1, it can be seen that input electricity bought from the utility significantly reduces during the daylight hours due to the working regime of BESS. The charge or discharge power of the BESS according to time is shown in Fig. 11. From 1 AM to $3 \mathrm{AM}, 7 \mathrm{AM}$ to $9 \mathrm{AM}$ and $9 \mathrm{PM}$ to $12 \mathrm{AM}$, the BESS stores energy because of low electricity prices during those times. This is used to supply load during high-cost times from 11 AM to 4 PM. It is noticed that in the peak hours, particularly from 5 PM to $8 \mathrm{PM}$, even though the cost of electricity is quite high in this period, the heating and cooling demands increase as well. Therefore, MT operates at maximum capacity to provide electricity and heat for loads as well as to satisfy the energy balance constraints of $\mathrm{EH}$

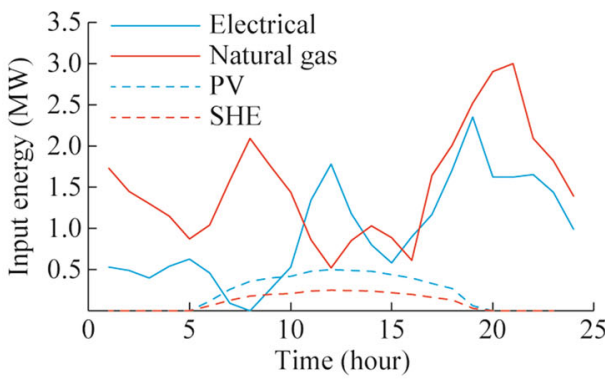

(b)

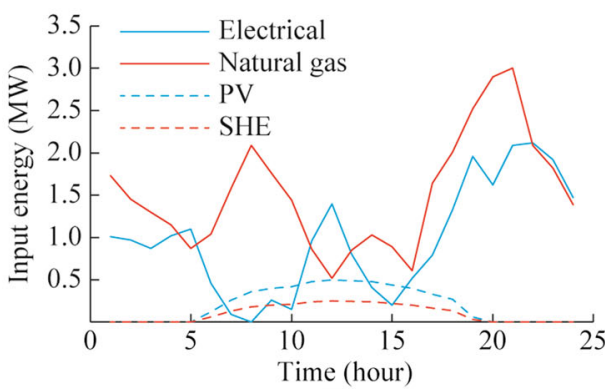

(d)

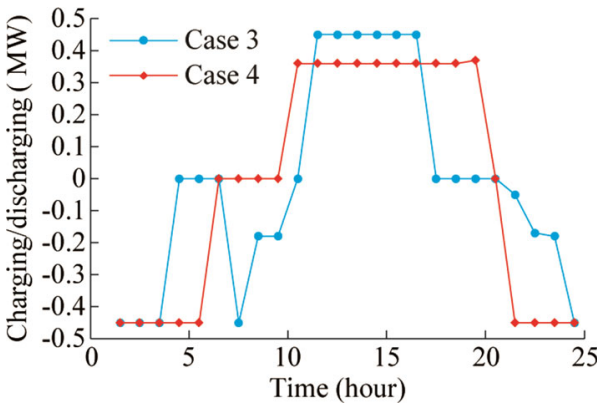

Fig. 11 Charging/discharging of BESS

model. The electricity energy is mainly supplied by MT, so BESS doesn't operate during these hours. In addition, based on the energy balance constraints of the BESS within a day, BESS has discharged all of the power that was stored from the previous hours to supply the loads at the peak hours during the time from $11 \mathrm{AM}$ to $4 \mathrm{PM}$. Therefore in this case, when the reduction of electricity price occurs (from $9 \mathrm{PM}$ to $12 \mathrm{AM}$ ), BESS will start the recharging process.

\subsubsection{Case 4}

Case 4 assesses the impact of solar energy and a BESS simultaneously on the optimal operation of an EH. The results show that the energy bought from utilities is reduced significantly compared to other cases (Fig.10), 
especially during the peak hours. The highest electricity input reached 2.12 MW during the off-peak period (10 PM). The optimized charge/discharge profile for the BESS is shown in Fig. 11. Due to the additional supply of PV energy and heat power of SHE, the operation of BESS is changed significantly, specifically during the time from 1 $\mathrm{AM}$ to $5 \mathrm{AM}$ and $9 \mathrm{PM}$ to $12 \mathrm{AM}$. The addition of solar PV input means that the energy capacity of the BESS is more effectively used, and the BESS continues to supply load throughout the peak hours with high electricity price (10 AM to 7 PM). The total cost of energy bought from utilities, in this case, is also the lowest as shown in Table 4. Therefore the EH including PV generation, SHE and a BESS brings greater efficiency than the remaining 3 cases.

\subsubsection{Discussion}

From the comparative study among the four cases, we can see that:

1) The proposed extended EH model is suitable for the diverse demands of residential load; simulation results show that the optimization model can respond quickly to the changing load and electricity price, allowing the model to consider the change of PV generation and SHE energy over time and season.

2) The comparative results of 4 cases with different structures clarify the role and influence of BESS and solar energy on the operational effectiveness of EH by minimizing the total cost of input energy (Table 4); reducing peak load demand leads to reduce sources and investment costs for power system upgrades.

Although the investment costs of the PV generation, SHE, and BESS equipment are quite high, the economic efficiency of EH operation shows that these costs would be partially offset by saved energy costs of the system. The result shows that the extended EH model is a useful contribution to the current trend of energy system development and renewable energy applications.

\section{Conclusion}

This research has solved the following two basic problems.

1) The first is a new structure for the EH model that fits with the characteristics of loads in residential areas. The proposed extended EH model exploits two types of solar energy through PV generation and SHE, while taking into account the use of electrical energy storage by using a BESS that has been previously used effectively in the distribution grid.
2) The second is an optimized operational model of EH with the objective to minimize total energy costs bought from utilities. Four cases with different structures have been set up to assess specifically the influence of solar energy and a BESS on the effectiveness of the EH operation. The optimization results show that the EH involving PV generation, SHE and a BESS could reduce total cost of energy bought from utilities by $15 \%$ while fully meeting the demand. This is a reliable basis for research and development of energy hubs using renewable energy.

It is shown that the structure of the EH greatly affects the operational efficiency. Therefore, further research on constructing optimal operational strategies for $\mathrm{EH}$ with different structures should be undertaken in order to provide specific assessments of the influence of each device in the model on the system's operation. Moreover, when considering the results of the EH model in this paper, although a survey has been conducted on the output power characteristics of PV generation and the average daily load profile, the load constantly changes with time due to features of residential demand. The generation characteristics of distributed generators depend heavily on primary and secondary energy sources, these generating characteristics need to be properly understood. Therefore, further research must be conducted to improve the EH model to include the uncertainty of both distributed generation and load.

Acknowledgements This work was supported by National Natural Science Foundation of China (No. 51377060).

Open Access This article is distributed under the terms of the Creative Commons Attribution 4.0 International License (http:// creativecommons.org/licenses/by/4.0/), which permits unrestricted use, distribution, and reproduction in any medium, provided you give appropriate credit to the original author(s) and the source, provide a link to the Creative Commons license, and indicate if changes were made.

\section{References}

[1] Moeini-Aghtaie M, Abbaspour A, Fotuhi-Firuzabad M et al (2014) A decomposed solution to multiple-energy carriers optimal power flow. IEEE Trans Power Syst 29(2):707-716

[2] Erdener BC, Pambour KA, Lavin RB et al (2014) An integrated simulation model for analysing electricity and gas systems. Electr Power Energy Syst 61:410-420

[3] Alipour M, Mohammadi-Ivatloo B, Zare K (2015) Stochastic scheduling of renewable and CHP-based microgrids. IEEE Trans Ind Inform 11(5):1049-1058

[4] Ren H, Gao W, Ruan Y (2008) Optimal sizing for residential CHP system. Appl Therm Eng 28:514-523

[5] Mohammadi-Ivatloo B, Moradi-Dalvand M, Rabiee A (2013) Combined heat and power economic dispatch problem solution 
using particle swarm optimization with time varying acceleration coefficients. Electr Power Syst Res 95:9-18

[6] Rastegar M, Fotuhi-Firuzabad M, Lehtonen M (2015) Home load management in a residential energy hub. Electr Power Syst Res 119:322-328

[7] Bozchalui MC, Canizares CA, Bhattacharya K (2015) Optimal energy management of greenhouses in smart grids. IEEE Trans Smart Grid 6(02):827-835

[8] Bozchalui MC, Hashmi SA, Hassen H et al (2012) Optimal operation of residential energy hubs in smart grid. IEEE Trans Smart Grid 3(4):1755-1766

[9] Le BS, Li R, Li F et al (2014) Cost and emission savings from the deployment of variable electricity tariffs and advanced domestic energy hub storage management. In: Proceedings of the 2014 IEEE PES general meeting conference \& exposition (PESGM'2014), Washington DC, USA, 27-31 July 2014, pp 1-5

[10] Ha TT, Zhang YJ, Huang JA et al (2016) Energy hub modeling for minimal energy usage cost in residential areas. In: Proceedings of the 2016 IEEE international conference on power and renewable energy (ICPRE'2016), Shanghai, China, 21-23 Oct 2016, pp 659-663

[11] International Energy Agency (2015) Photovoltaic power systems programme (PSPV) trends 2015 in photovoltaic application. Report IEA-PVPS T1-27:2015

[12] Kannan N, Vakeesan D (2016) Solar energy for future world: A review. Renew Sustain Energy Rev 62:1351-1366

[13] Kazemi A, Sadeghi M (2009) Sitting and sizing of distributed generation for loss reduction. In: Proceedings of the Asia-Pacific power and energy engineering conference (APPEEC'2009), Wuhan, China, 27-31 March 2009, pp 1-4

[14] Geidl M, Koeppel G, Favre-Perrod P et al (2007) Energy Hubs for the future. IEEE Power Energy Mag 5(1):24-30

[15] Favre-Perrod P (2005) A vision of future energy networks. In: Proceedings of the 2005 IEEE power engineering society inaugural conference and exposition in Africa, Durban, 11-15 July 2005, pp 13-17

[16] Hida Y, Ito Y, Yokoyama R et al (2010) A study of optimal capacity of PV and battery energy storage system distributed in demand side. In: Proceedings of the 45th international universities power engineering conference (UPEC'2010), Cardiff, Wales, Aug 31-Sept 3 2010, pp 1-5

[17] Lu B, Shahidehpour M (2005) Short-term Scheduling of battery in a grid-connected PV/battery system. IEEE Trans Power Syst 20(2):1053-1061

[18] Leou RC (2008) An economic analysis model for the energy storage systems in a deregulated market. In: Proceedings of the 2008 IEEE international conference on sustainable energy technologies (ICSET'2008), Singapore, 24-27 Nov 2008, pp 744-749

[19] Zeng J, Zhang B, Mao C et al (2006) Use of battery energy storage system to improve the power quality and stability of wind farms. In: Proceedings of the 2006 IEEE international conference on power system technology (ICPST'2006), Chongqing, China, 22-26 Oct 2006, pp 1-6

[20] Pazouki S, Haghifam MR (2015) Scheduling of energy hubs including CCHP, solar and energy storages in different climates. In: Proceedings of the 2015 IEEE 20th Iranian electrical power distribution conference (EPDC'2015), Zahedan, Iran, 28-29 April 2015, pp 101-106

[21] Bahrami S, Safe F (2013) A financial approach to evaluate an optimized combined cooling, heat and power system. Energy Power Eng 5:352-362

[22] Shen XW, Han YD, Zhu SZ et al (2015) Comprehensive powersupply planning for active distribution system considering cooling, heating and power load balance. J Mod Power Syst Clean Energy 3(4):485-493. doi:10.1007/s40565-0150164-5

[23] Liu MX, Yg Shi, Fang F (2014) Combined cooling, heating and power systems. Renew Sustain Energy Rev 35:1-22

[24] Valipour M (2016) Optimization of neural networks for precipitation analysis in a humid region to detect drought and wet year alarms. Meteorol Appl 23:91-100

[25] Yannopoulos SI, Lyberatos G, Theodossiou N et al (2015) Evolution of water lifting devices (pumps) over the centuries worldwide. Water 7:5031-5060

[26] Valipour M (2014) Application of new mass transfer formulae for computation of evapotranspiration. J Appl Water Eng Res 2:33-46

[27] Wang Y, Zhang N, Kang CQ (2015) Review and prospect of optimal planning and operation of energy hub in energy internet. China Soc Electr Eng 35(22):5669-5681

[28] Shahmohammadi A, Moradi-Dalvand M, Ghasemi $\mathrm{H}$ et al (2015) Optimal design of multicarrier energy systems considering reliability constraints. IEEE Trans Power Deliv 30(2): 878-886

[29] Pazouki S, Mohsenzadeh A, Ardalan S et al (2016) Optimal place, size, and operation of combined heat and power in multi carrier energy networks considering network reliability, power loss, and voltage profile. Inst Eng Technol 10(7): $1615-1621$

[30] Brooke A, Kendrick D, Meeraus A et al (2003) GAMS a user's guide, GAMS development Corp, Washington, DC

[31] Xu XD, Jia HJ, Jin XL et al (2015) Study on hybrid heat-gaspower flow algorithm for integrated community energy system. China Soc Electr Eng 35(14):3634-3642

[32] Jamali AA, Nor NM, Ibrahim T (2015) Energy storage systems and their sizing techniques in power system-a review. In: Proceedings of the 2015 IEEE conference on energy conversion (CENCON'2015), Johor Bahru, Malaysia, 19-20 Oct 2015, pp 215-220

[33] Medina P, Bizuayehu AW, Catalao JPS et al (2014) Electrical energy storage systems: technologies' state-of-the-art, techno-economic benefits and applications analysis. In: Proceedings of the 47th Hawaii international conference on system sciences (HICSS), Waikoloa, HI, USA, 6-9 Jan 2014, pp 2295-2304

[34] Zakeri B, Syri S (2015) Corrigendum to "electrical energy storage systems: a comparative life cycle cost analysis". Renew Sustain Energy Rev 42:569-596

[35] Poullikkas A (2013) A comparative overview of large-scale battery systems for electricity storage. Renew Sustain Energy Rev 27:778-788

[36] Zhou Z, Benbouzid M, Charpentier JF et al (2013) A review of energy storage technologies for marine current energy systems. Renew Sustain Energy Rev 18:390-400

[37] Beardsall JC, Gould CA, Al-Tai M (2015) Energy storage systems: a review of the technology and its application in power systems. In: Proceedings of the 2015 IEEE 50th international universities power engineering conference (UPEC'2015), Stoke on Trent, UK, 1-4 Sept. 2015, pp 1-6

[38] Tang Y, Song H, Hu F et al (2005) Investigating on TOU pricing principles. In: Proceedings of the 2005 IEEE/PES transmission \& distribution conference \& exposition: Asia and Pacific (T\&D Asia), Dalian, China, 2005, pp 1-9

[39] Home Electricity Price (2014). http://www.opc.state.md.us/ ConsumerCorner/Electricity.aspx. Accessed 20 Oct 2016

[40] Gas Commodity Fact Sheet for Maryland Public Service Commission (2014). http://www.psc.state.md.us/gas/. Accessed 20 Oct 2016 
Thanhtung HA received the B.Sc. and M.Sc. degrees in the Department of Electric Power Systems at Thai Nguyen University of Technology (TNUT), Vietnam, in 2009 and 2012, respectively. He is currently pursuing Ph.D. Degree in Electrical Engineering at South China University of Technology. His research interests include analyzing and controlling the operation of energy system.

Yongjun ZHANG received the Ph.D. degree in power system and its automation from the South China University of Technology, Guangzhou, China, in 2004. From 1995 to 2005, he was a Research Assistant in School of Electric Power, South China University of Technology. From 2005 to 2012, he was an Assistant Professor. Since 2012, he has been a Professor at the same university. He has been the author of three books and more than 100 articles. His research interests include power system reactive power optimization, distributed generation control and optimization, voltage control, energy saving, and high-voltage direct current transmission.
V. V. THANG received the B.Sc. and M.Sc. degrees in the Department of Electric Power Systems, Thai Nguyen University of Technology (TNUT), Vietnam, in 2001 and 2007, respectively. He received the Ph.D. Degree at the Hanoi University of Science and Technology (HUST) in 2015. He is currently a lecturer in the Department of Electric Power System at TNUT. His major research interests include optimizing energy systems, distributed generations and distribution systems in deregulated electricity markets.

Jianang HUANG received the B.Sc. degree in Electrical Engineering and its automation from South China University of Technology, Guangzhou, China, in 2015. He is currently pursuing the M.Sc. degree in Electrical Engineering at South China University of Technology. His research interests include key technologies of the smart distribution system and renewable energy. 